\title{
ANALISIS MODEL PROYEKSI LADA SEBAGAI KAJIAN DIVERSIFIKASI SEKTOR PENDAPATAN MASYARAKAT DI PROVINSI KEPULAUAN BANGKA BELITUNG
}

\author{
Analysis of Pepper Model Projections as a Study of Community Income Sector \\ Diversification in the Province of Bangka Belitung
}

\author{
Sisilia Jesika Pririzki ${ }^{1}$, Ilam Maryam ${ }^{2}$, Pitra Wati ${ }^{3}$, Desy Yuliana Dalimunthe ${ }^{4^{*}}$ \\ 1,2,3,4 Jurusan Matematika, Fakultas Teknik, Universitas Bangka Belitung \\ Jalan Kampus Terpadu Universitas Bangka Belitung, Kelurahan Balunijuk, \\ Kecamatan Merawang, Kabupaten Bangka, 33172, Indonesia
}

Corresponding author e-mail: ${ }^{4 *}$ desydalimunthe2@gmail.com

\begin{abstract}
Abstrak
Provinsi Kepulauan Bangka Belitung merupakan provinsi dengan pendapatan masyarakatnya bergantung pada sektor pertanian, yaitu lada. Penelitian ini bertujuan untuk memperoleh nilai proyeksi produksi lada di Provinsi Kepulauan Bangka Belitung pada Tahun 2022 yang selama ini menjadi komoditas utama dari sisi sektor pendapatan masyarakat dan juga merupakan bagian dari proses diversifikasi agar masyarakat setempat tidak bergantung dari satu sektor pertanian saja dalam memenuhi kebutuhan sehari-hari. Metode exponential smoothing yang digunakan dalam penelitian ini terdiri dari beberapa model, yakni simple, holt, dan brown exponential smoothing. Dari ketiga model ini akan ditentukan model peramalan yang terbaik (fitting model) dengan menggunakan hasil Root Mean Square Error (RMSE) yang terkecil dari ketiga model tersebut. Berdasarkan proses fitting model yang dilakukan, model holt merupakan model terbaik dengan nilai MSE 7.425,298 dan juga memberikan hasil bahwa komoditas lada ini mengalami penurunan sebesar 17,56\% pada tahun 2021 dan juga mengalami penurunan sebesar $21,30 \%$ pada tahun 2022 .
\end{abstract}

Kata Kunci : Lada, forecasting, exponential smoothing, Holt

\begin{abstract}
The Province of the Bangka Belitung Islands is a province where people's incomes depend on the agricultural sector, namely pepper. This study aims to obtain the projected value of pepper production in the Province of the Bangka Belitung Islands in 2022 which has been the main commodity in terms of the community income sector and is also part of the diversification process so that local communities do not depend on one agricultural sector alone to meet their daily needs. day. The exponential smoothing method used in this study consists of several models, namely simple, holt, and brown exponential smoothing. From these three models, the best forecasting model (fitting model) will be determined using the smallest Root Mean Square Error (RMSE) of the three models. Based on the model fitting process carried out, the holt model is the best model with an MSE value of 7,425,298 and also gives the result that this pepper commodity has decreased by $17.56 \%$ in 2021 and also decreased by $21.30 \%$ in 2022.
\end{abstract}

Keywords: pepper, forecasting, exponential smoothing, Holt

S. J. Pririzki, I. Maryam, P. Wati, and D. Y. Dalimunthe, "ANALISIS MODEL PROYEKSI LADA SEBAGAI KAJIAN DIVERSIFIKASI SEKTOR PENDAPATAN MASYARAKAT DI PROVINSI KEPULAUAN BANGKA BELITUNG”, BAREKENG: J. Il. Mat. \& Ter., vol. 15, no. 02, pp. 249-256, Jun. 2021.

\section{(i) (2)}

This work is licensed under a Creative Commons Attribution-ShareAlike 4.0 International License.

Copyright @ 2021 Sisilia Jesika Pririzki, Ilam Maryam, Pitra Wati, Desy Yuliana Dalimunthe 


\section{PENDAHULUAN}

Pulau Bangka dan Pulau Belitung merupakan dua pulau yang membentuk Provinsi Kepulauan Bangka Belitung dengan luas wilayah sebesar $81.725,23 \mathrm{~km}^{2}$ [1]. Di sisi lain, Perkebunan merupakan sub sektor utama dengan konstribusi terhadap Produk Domestik Regional Bruto (PDRB) mencapai 19,01\%. Salah satu komoditas yang menjadi unggulan dan prioritas pembangunan di Bangka Belitung yaitu lada putih. Lada putih dikenal dan diusahakan sejak dulu di pasar internasional dengan branding "Muntok White Pepper" yang telah memiliki sertifikat Indikasi Geografis (IG), yaitu dengan ciri khas lada lebih pedas dari jenis lada lainnya. Lada putih telah memberikan konstribusi nyata sebagai sumber devisa, penyedia lapangan kerja, bahan baku industri, dan sumber pendapatan petani. Pengembangan kawasan peruntukan pertanian dilakukan melalui penetapan kawasan peruntukan pertanian pangan berkelanjutan sebagai bagian dari pertahanan pangan nasional [1]. Produksi lada putih di provinsi ini dapat mencapai sekitar 80-97\% atau 62.000 ton per tahun dari total produksi lada putih Indonesia pada tahun 1987 hingga 2002.

Provinsi Kepulauan Bangka Belitung dikenal sebagai salah satu sentra produksi lada di Indonesia, khusunya lada putih. Namun, dewasa ini luas areal dan produksi lada putih di Provinsi Kepulauan Bangka Belitung terus menurun karena berbagai sebab, antara lain fluktuasi harga lada, gangguan organisme penggangguan tanaman, dampak penambangan timah illegal dan introduksi tanaman perkebunan lain. Bila kondisi demikian dibiarkan berkepanjangan maka tidak mustahil peran lada putih dari Provinsi Kepulauan Bangka Belitung akan semakin kritis atau bahkan hilang [2].

Pertambahan penduduk akan mengakibatkan permintaan lada semakin meningkat pula, hal ini bisa kita lihat dari perilaku konsumsi manusia dan beraneka ragamnya jenis makanan yang ditawarkan [3]. Adanya peran penyuluh pertanian yang belum optimal dapat menyebabkan lada putih saat ini mengalami penurunan dari sisi produksi, ekspor, dan harga [4]. Walaupun dari sisi produksi, ekspor, dan harga lada mengalami penurunan, Provinsi Kepulauan Bangka Belitung juga memiliki hasil yang cukup baik sperti penelitian yang dilakukan oleh Desy Yuliana, dkk [5] begitupun lanjutan dari hasil penelitian ini seperti yang dilakukan oleh Devi Valeriani, dkk [6]. Dari tahun ke tahun produksi lada di Bangka Belitung ini tidak mengalami peningkatan yang kosisten karena terdapat beberapa tahun produksi lada di Provinsi Kepulauan Bangka Belitung juga mengalami penurunan. Hal ini dapat terlihat dari data produksi lada di Kepulauan Bangka Belitung Tahun 2001- 2020 yang didapatkan dari Dinas Pertanian, Perkebunan, dan Perternakan Provinsi Kepulauan Bangka Belitung.

Penelitian yang sejalan dengan model proyeksi dengan menggunakan metode Pemulusan Eksponensial antara lain penelitian yang dilakukan oleh Desy Yuliana dan Herman Aldila pada Tahun 2019 mengenai proyeksi konsumsi energi menggunakan model exponential smoothing [7]. Selain itu hal yang serupa juga pernah dilakukan dalam melakukan fitting model mengenai angka kemiskinan yang terjadi di Provinsi Kepulauan Bangka Belitung [8]. Dalam bidang ekonomi juga banyak sekali implementasi dari model proyeksi ini, salah satunya dengan mengimplementasikan model proyeksi untuk melihat proyeksi dari nilai Produk Domestik regional Bruto (PDRB) Provinsi Kepulauan Bangka Belitung dengan hasil bahwa PDRB Provinsi ini mengalami tren naik dengan menggunakan model penelitian ARIMA [9]. Dalam bidang sosial lain juga terdapat beberapa penerapan dari data-data time series yang tidak hanya terbatas dalam sisi proyeksi saja, tetapi juga bisa menerapkan metode-metode lain misalnya Vector Auto Regression (VAR) [10].

Proyeksi (Projection) merupakan kegiatan memprediksi nilai-nilai sebuah variabel berdasarkan nilai yang diketahui dari variabel tersebut atau variabel yang berhubungan. Metode kausal mempertimbangkan nilai sebuah variabel sebagai pengaruh dari banyak variabel yang lain. Sedangkan metode time series hanya meninjau nilai sebuah variabel sebagai fungsi waktu [8]. Peramalan juga merupakan alat bantu yang penting dalam perancanaan yang efektif dan efisien [9].

Proyeksi yang menggunakan metode Pemulusan Eksponensial (Exponential Smoothing) merupakan salah satu kategori metode time series yang menggunakan pembobotan data masa lalu secara eksponensial. Dalam metode eksponential smoothing ini mengandalkan tiga model dasar, diantaranya simple eksponential smoothing, tren eksponential smoothing dan musiman eksponential smoothing [13].

Exponential smoothing merupakan salah satu metode untuk memperoleh proyeksi data tahun kedepan dari data time series dimana prosedur perbaikan terus menerus terhadap objek pengamatan terbaru. Metode ini menitik-beratkan pada penurunan prioritas secara eksponensial pada objek pengamatan yang lebih tua. Dengan kata lain, observasi terbaru akan diberikan prioritas lebih tinggi bagi peramalan daripada 
observasi yang lebih lama. Lebih lanjut, elemen dalam peramalan itu menarik dan baru karena terdapat ideide baru dalam grafis dan saran baru dalam penyajiannya [14].

Berdasarkan deskripsi di atas penulis memiliki tujuan yakni untuk mengetahui alasan dilakukannya proyeksi mengenai jumlah lada putih yang dihasilkan serta untuk mengetahui seberapa tepatkah kegiatan pertanian lada sehingga dapat dijadikan wadah untuk penghasilan masyarakat Bangka Belitung. Dengan harapan dapat membantu dalam pengambilan keputusan bagi Pemerintah Pusat dan Pemerintah Daerah dalam pengambilan keputusan terkait peralihan mata pencaharian dari sektor pertambangan ke sektor pertanian. Selain itu, juga dapat mengubah paradigma masyarakat yang masih ketergantungan di satu mata pencaharian di sektor pertanian.

\section{METODE PENELITIAN}

Adapun tahapan penelitian ini terdiri dari empat tahap yaitu : Studi Literatur, Pengumpulan data, Analisis data dan Validasi Model Proyeksi. Pada studi Literatur akan dilakukannya proses mencari, mencatat dan mengumpulkan data. Adapun data yang digunakan dalam penelitian ini adalah data sekunder yakni data produksi lada di Provinsi Kepulauan Bangka Belitung Tahun 2001- 2020 yang didapatkan dari Dinas Pertanian, Perkebunan, dan Perternakan Provinsi Kepulauan Bangka Belitung. Data sekunder ini bersifat time series (runtun waktu) yang diolah dengan bantuan software SPSS untuk memperoleh nilai proyeksi dari lada di Provinsi Kepulauan Bangka Belitung menggunakan metode Pemulusan Eksponensial (Exponential Smoothing). Dimana metode ini memiliki tiga model yang berbeda, yaitu simple, holt, dan brown. Dari ketiga model tersebut akan di analisis model mana yang terbaik. Untuk melakukan fitting model ini paling sering digunakan alat ukur menggunakan MAPE (Mean Absolute Percentage Error) sebagai tolak ukur keakuratan dalam melakukan proyeksi [15].

Secara umum memang metode ini merupakan salah satu metode proyeksi yang relatif sederhana namun kuat untuk dilakukan peramalan [13]. Metode proyeksi yang digunakan dalam penelitian ini menggunakan metode Pemulusan Eksponensial Tunggal (Single Exponential Smoothing) untuk data runtut waktu yang mengikuti pola stasioner dengan bentuk persamaan sebagai berikut:

$$
Y_{t+1}^{\wedge}=\alpha Y_{t}+(1-\alpha) Y_{t}^{\wedge}
$$

Dimana:

$Y_{t+1}^{\wedge}=$ nilai ramalan untuk periode berikutnya

$\alpha \quad=$ konstanta pemulusan

$Y_{t} \quad=$ data baru atau nilai $Y$ yang sebenarnya pada periode $t$

$Y_{t}^{\wedge} \quad=$ nilai pemulusan yang lama atau rata-rata pemulusan hingga periode $t-1$

Metode Pemulusan Eksponensial Ganda Satu Parameter dari Brown (Brown's One-Parameter Double Exponential Smoothing) Bentuk umum yang digunakan untuk menghitung forecast pada periode ke sebagai berikut:

$$
Y_{t+p}^{\wedge}=a_{t}+b_{t} p
$$

Dimana :

$a_{t} \quad=$ perbedaan antara nilai-nilai pemulusan eksponensial

$b_{t} \quad=$ faktor penyesuai tambahan $=$ pengukuran slope suatu kurva

$Y_{t} \quad=$ nilai aktual pada periode $t$

$p \quad=$ jumlah periode ke depan yang akan diramalkan

Metode selanjutnya adalah metode Pemulusan Ganda Dua Parameter dari Holt (Holt's TwoParameter Double Exponential Smoothing) yang digunakan dalam peramalan data runtut waktu yang mengikuti suatu tren linier. Bentuk umum yang digunakan untuk menghitung peramalan pada periode $p$ yang akan datang adalah:

$$
Y_{t+p}=A_{t}+T_{t} p
$$

Dimana :

$A_{t}=$ nilai pemulusan eksponensial 
$Y_{t}=$ nilai aktual pada periode $t$

$T_{t}=$ estimasi trend

$p=$ jumlah periode ke depan yang akan diramalkan

Agar dapat memulai sistem peramalan metode Brown kita memerlukan $\mathrm{A}_{1}$, karena $A_{2}=\alpha Y_{1}+(1-\alpha)\left(A_{1}\right.$ $+T_{1}$ ), karena pada saat $\mathrm{t}=1$, nilai $\mathrm{A}_{1}$ tidak diketahui, maka kita dapat menggunakan nilai observasi pertama $\left(\mathrm{Y}_{1}\right)$. Untuk estimasi tren pada saat $\mathrm{t}=1$, nilai $\mathrm{T}_{1}$ tidak diketahui, maka kita dapat menggunakan selisih nilai observasi kedua $\left(\mathrm{Y}_{2}\right)$ dengan nilai observasi pertama $\left(\mathrm{Y}_{1}\right)$, yaitu $\mathrm{T}_{1}=\mathrm{Y}_{2}-\mathrm{Y}_{1}$. Metode terakhir dari pemulusan eksponensial ini yakni Pemulusan Eksponensial Tripel dari Winter (Winter's Three-Parameter Triple Exponential Smoothing) Digunakan dalam peramalan data runtut waktu yang mengikuti suatu pola musiman. Didasarkan pada 3 persamaan pemulusan, yaitu: untuk unsur stasioner, untuk tren, dan untuk musiman. Bentuk umum yang digunakan untuk menghitung ramalan pada periode $p$ yang akan datang adalah:

$$
Y_{t+p}^{\wedge}=\left(a_{t}+T_{t} p\right) S_{t}-L+p
$$

Dimana:

$A_{t} \quad=$ nilai pemulusan eksponensial

$Y_{t} \quad=$ nilai aktual pada periode $t$

$T_{t} \quad=$ estimasi trend

$S_{t} \quad=$ estimasi musiman

$L \quad$ = panjangnya musim

$p \quad=$ jumlah periode ke depan yang akan diramalkan

\section{HASIL DAN PEMBAHASAN}

Pada penelitian ini akan dilakukannya analisis model proyeksi lada sebagai kajian diversifikasi sektor pendapatan masyarakat di Provinsi Kepulauan Bangka Belitung. Sebelum melakukan suatu analisis data, langkah pertama yang harus di dapatkan adalah data mentah dari objek yang akan diteliti. Dalam penelitian ini didapatkan data mentah berupa data produksi lada di Provinsi Kepulauan Bangka Belitung Tahun 20012020 yang didapatkan dari Dinas Pertanian, Perkebunan, dan Perternakan Provinsi Kepulauan Bangka Belitung.

Pada penelitian kali ini diharapkan akan mendapatkan hasil proyeksi lada di Tahun 2021 dan 2022. Pada penelitian ini peneliti menggunakan metode exponential smoothing. Metode ini hanya bisa memproyeksikan satu tahun kedepan. Pada metode exponential smoothing ini terdapat tiga model. Ketiga model ini yaitu simple, holt, dan brown exponential smoothing. Dari ketiga model pada metode exponential smoothing ini akan dicari model peramalan yang terbaik. Dalam proses fitting model ini akan dilihat dari nilai Root Mean Squared Eror (RMSE) yang akan di cari nilai terkecilnya.

Tabel 1. Nilai RMSE dari ketiga model pada metode exponential smoothing

\begin{tabular}{cc}
\hline Model & $\boldsymbol{R M S E}$ \\
\hline Simple & $8.330,209$ \\
\hline Holt & $7.425,298$ \\
\hline Brown & $7.553,656$
\end{tabular}

Berdasarkan Tabel 1 diatas disajikan nilai RMSE dari masing-masing model pada metode exponential smoothing. Dengan mengetahui nilai RMSE, maka dapat ditentukan model mana yang memiliki fit values. Dikarenakan pada model Holt memiliki nilai RMSE terkecil, sehingga model yang terbaik adalah model Holt. Selanjutnya akan dilakukan proyeksi produksi lada untuk Tahun 2021 dan 2022 menggunakan model Holt.

Sebelum mencari proyeksi produksi lada di tahun 2021 dan 2022, maka harus didefinisikan terlebih dahulu waktu dalam memproyeksikannya. Pada penelitian kali ini waktu didefinisikan dalam tahun atau years. Langkah awal yang dilakukan adalah memilih menu analyze, kemudian pilih forecasting dilanjutkan dengan memilih deifine date and time, dan pilih yang years. Setelah di definisikan, Selanjutnya akan dilakukan proyeksi dengan bantuan software SPSS untuk mengetahui produksi lada di Tahun 2021 dan 
2022. Didapatkan hasil proyeksi produksi lada di Tahun 2021 dan 2022 adalah 14177 dan 11157. Sehingga dapat dilihat data proyeksi lada dari Tahun 2001-2022 pada Tabel 3.2.

Tabel 2. Data proyeksi lada dari Tahun 2001-2022

\begin{tabular}{cc}
\hline Tahun & Produksi Lada (Ton) \\
\hline $\mathbf{2 0 0 1}$ & 63694 \\
\hline $\mathbf{2 0 0 2}$ & 32610 \\
\hline $\mathbf{2 0 0 3}$ & 27566 \\
\hline $\mathbf{2 0 0 4}$ & 22140 \\
\hline $\mathbf{2 0 0 5}$ & 20781 \\
\hline $\mathbf{2 0 0 6}$ & 11654 \\
\hline $\mathbf{2 0 0 7}$ & 16424 \\
\hline $\mathbf{2 0 0 8}$ & 15671 \\
\hline $\mathbf{2 0 0 9}$ & 15601 \\
\hline $\mathbf{2 0 1 0}$ & 18472 \\
\hline $\mathbf{2 0 1 1}$ & 28242 \\
\hline $\mathbf{2 0 1 2}$ & 34379 \\
\hline $\mathbf{2 0 1 3}$ & 33596 \\
\hline $\mathbf{2 0 1 4}$ & 33828 \\
\hline $\mathbf{2 0 1 5}$ & 31408 \\
\hline $\mathbf{2 0 1 6}$ & 29264 \\
\hline $\mathbf{2 0 1 7}$ & 26247 \\
\hline $\mathbf{2 0 1 8}$ & 23229 \\
\hline $\mathbf{2 0 1 9}$ & 20217 \\
\hline $\mathbf{2 0 2 0}$ & 17197 \\
\hline $\mathbf{2 0 2 1}$ & 14177 \\
\hline $\mathbf{2 0 2 2}$ & 11157 \\
\hline & \\
\hline
\end{tabular}

Jika dilihat dari Tabel 2 diatas dapat diketahui bahwa produksi lada mengalami naik dan turun tiap tahunnya. Untuk data produksi lada pada Tahun 2021 dan 2022 yang telah dilakukan proyeksi mengalami penurunan. Hal ini bisa menjadi pertimbangan masyarakat di Provinsi Kepulauan Bangka Belitung agar tidak hanya terfokus pada satu sektor mata pencaharian saja yakni lada dan dapat melakukan diversifikasi di sektor pertanian lainnya seperti sawit, karet atau sektor pertambangan yaitu timah. Gambar 4.1 dibawah ini menunjukkan terjadinya fluktuasi produksi lada di Provinsi Kepulauan Bangka Belitung dalam kurun waktu 19 Tahun.

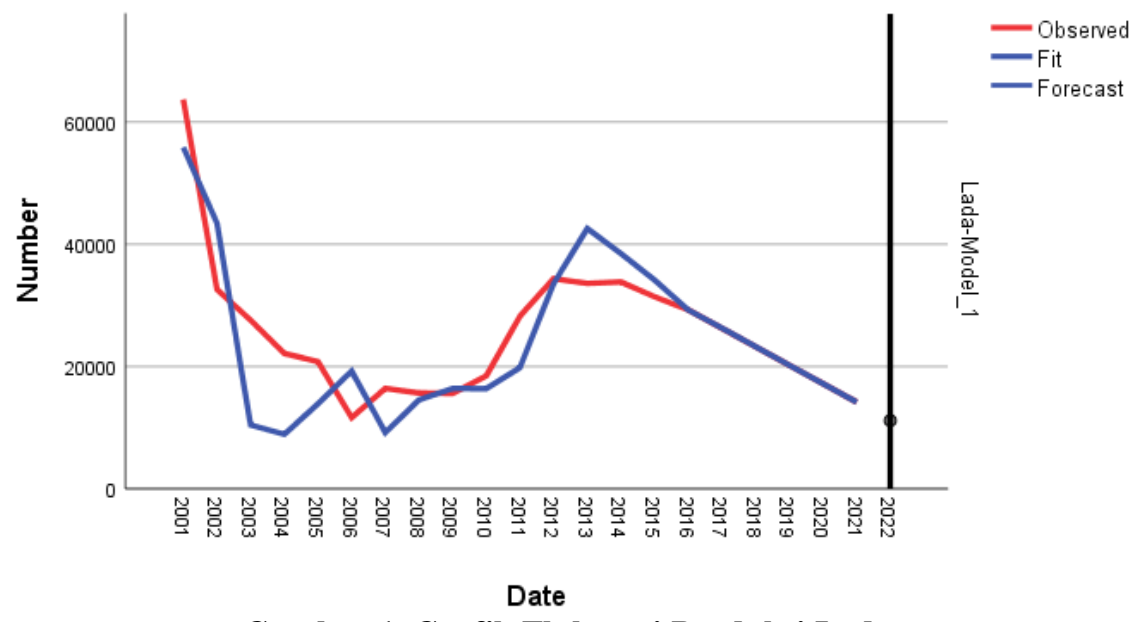

Gambar 1. Grafik Fluktuasi Produksi Lada

Selain menentukan nilai prediksi produksi lada di Tahun 2021 dan 2022, akan ditentukan pula Lower Control Limit (LCL) dan Upper Control Limit (UCL) di Tahun 2021 dan 2022. Nilai LCL ini merupakan batas minimum produksi lada yang di prediksi dan sebaliknya nilai $U C L$ merupakan batas maksimum 
produksi lada. Pada Tabel 3 akan disajikan $L C L$ dan $U C L$ di Tahun 2021 dan pada Tabel 4 akan disajikan $L C L$ dan $U C L$ di Tahun 2022.

Tabel 3. Nilai Prediksi Lada, $L C L$ dan $U C L$ di Tahun 2021

\begin{tabular}{|c|c|c|c|}
\hline Waktu & Prediksi Lada (Ton) & $L C L$ & $U C L$ \\
\hline 2001 & 63694 & 40266 & 71466 \\
\hline 2002 & 32610 & 27844 & 59044 \\
\hline 2003 & 27566 & -5177 & 26023 \\
\hline 2004 & 22140 & -6688 & 24512 \\
\hline 2005 & 20781 & -1695 & 29505 \\
\hline 2006 & 11654 & 3664 & 34864 \\
\hline 2007 & 16424 & -6408 & 24791 \\
\hline 2008 & 15671 & -1064 & 30136 \\
\hline 2009 & 15601 & 815 & 32015 \\
\hline 2010 & 18472 & 764 & 31964 \\
\hline 2011 & 28242 & 4226 & 35426 \\
\hline 2012 & 34379 & 17971 & 49171 \\
\hline 2013 & 33596 & 26967 & 58167 \\
\hline 2014 & 33828 & 22869 & 54068 \\
\hline 2015 & 31408 & 18554 & 49754 \\
\hline 2016 & 29264 & 13645 & 44845 \\
\hline 2017 & 26247 & 10681 & 41881 \\
\hline 2018 & 23229 & 7655 & 38855 \\
\hline 2019 & 20217 & 4617 & 35817 \\
\hline 2020 & 17197 & 1597 & 32797 \\
\hline 2021 & 14177 & -1423 & 29777 \\
\hline
\end{tabular}

Selanjutnya, Tabel 4 dibawah ini merupakan nilai prediksi, lCL, dan UCL produksi lada pada Tahun 2022.

Tabel 4. Nilai Prediksi Lada, $L C L$ dan $U C L$ di Tahun 2022

\begin{tabular}{cccc}
\hline Waktu & Prediksi Lada (Ton) & $\boldsymbol{L C} \boldsymbol{U}$ & $\boldsymbol{U} \boldsymbol{L}$ \\
\hline $\mathbf{2 0 0 1}$ & 55866 & 40739 & 70993 \\
\hline $\mathbf{2 0 0 2}$ & 43444 & 28317 & 58571 \\
\hline $\mathbf{2 0 0 3}$ & 10423 & -4704 & 25550 \\
\hline $\mathbf{2 0 0 4}$ & 8912 & -6214 & 24039 \\
\hline $\mathbf{2 0 0 5}$ & 13905 & -1222 & 29032 \\
\hline $\mathbf{2 0 0 6}$ & 19264 & 4137 & 34391 \\
\hline $\mathbf{2 0 0 7}$ & 9192 & -5935 & 24318 \\
\hline $\mathbf{2 0 0 8}$ & 14536 & -591 & 29663 \\
\hline $\mathbf{2 0 0 9}$ & 16415 & 1288 & 31541 \\
\hline $\mathbf{2 0 1 0}$ & 16364 & 1237 & 31491 \\
\hline $\mathbf{2 0 1 1}$ & 19826 & 4699 & 34953 \\
\hline $\mathbf{2 0 1 2}$ & 33571 & 18444 & 48698 \\
\hline $\mathbf{2 0 1 3}$ & 42567 & 27440 & 57694 \\
\hline $\mathbf{2 0 1 4}$ & 38468 & 23342 & 53595 \\
\hline $\mathbf{2 0 1 5}$ & 34154 & 19027 & 49280 \\
\hline $\mathbf{2 0 1 6}$ & 29245 & 14118 & 44371 \\
\hline
\end{tabular}




\begin{tabular}{cccc}
\hline Waktu & Prediksi Lada (Ton) & $\boldsymbol{L C L}$ & $\boldsymbol{U C L}$ \\
\hline $\mathbf{2 0 1 7}$ & 26281 & 11154 & 41408 \\
\hline $\mathbf{2 0 1 8}$ & 23255 & 8129 & 38382 \\
\hline $\mathbf{2 0 1 9}$ & 20217 & 5090 & 35344 \\
\hline $\mathbf{2 0 2 0}$ & 17197 & 2070 & 32324 \\
\hline $\mathbf{2 0 2 1}$ & 14177 & -950 & 29304 \\
\hline $\mathbf{2 0 2 2}$ & 11157 & -3970 & 26284 \\
\hline
\end{tabular}

\section{KESIMPULAN}

Berdasarkan hasil dan pembahasan yang telah dilakukan maka dapat disimpulkan beberapa hal sebagai berikut:

1) Pola data time series dari data yang digunakan dalam penelitian ini memiliki pola data fluktuatif.

2) Proses Fitting model dari tiga jenis model eksponential smoothing, yakni simple eksponential smoothing, Holt eksponensial smoothing dan Brown eksponential smoothing diperoleh hasil bahwa model Holt eksponential smoothing memiliki nilai RMSE terkecil dibandingkan dengan dua jenis model lainnya yakni sebesar 7425,298.

3) Berdasarkan hasil forecasting dengan menggunakan model Holt, hasil lada mengalami penurunan sebesar 17,56\% pada tahun 2021 dan juga mengalami penurunan sebesar $21,30 \%$ pada tahun 2022.

4) Hasil proyeksi ini sejalan dengan program pemerintah yang menyatakan bahwa untuk menjaga pertumbuhan ekonomi perlu adanya perubahan pola pikir masyarakat dari yang hanya berfokus pada urusan budidaya pertanian saja menjadi lebih memikirkan aspek komersialisasi dan pemasaran hasil pertanian. Selain itu kelompok tani juga disarankan agar dapat berkembang lebih jauh dengan didampingi oleh BUMN, BUMD, dan pihak swasta.

5) Perlu adanya diversifikasi sektor pendapatan masyarakat yang tidak hanya bersumber dari sektor produksi lada saja, melainkan juga dapat berasal dari sektor pertanian lainnya seperti karet, sawit, dan sektor diluar sektor pertanian misalnya sektor pertambangan, sektor perikanan dan sebagainya.

\section{UCAPAN TERIMA KASIH}

Ucapan terimakasih disampaikan kepada semua pengulas yang telah menyumbangkan kehalian dan waktu untuk proses penulisan terutama kepada Unit Pengelola Kegiatan Mahasiswa (UPKM) Fakultas Teknik Universitas Bangka Belitung. Terimakasih juga disampaikan karena telah berupaya dalam mengevaluasi dan menilai artikel yang diajukan untuk dipertimbangkan dalam proses publikasi.

\section{DAFTAR PUSTAKA}

[1] Pemerintah Provinsi Kepulauan Bangka Belitung, "Peraturan Daerah Provinsi Kepulauan Bangka Belitung Nomor 14 Tahun 2017."

[2] D. A. N. A. Pemulihannya, U. Daras, and D. Pranowo, "Kondisi Kritis Lada Putih Bangka Belitung Dan Alternatif Pemulihannya," J. Penelit. dan Pengemb. Pertan., vol. 28, no. 1, pp. 1-6, 2017, doi: 10.21082/jp3.v28n1.2009.p1-6.

[3] R. ElIZABETH, "Keragaan Komoditas Lada Indonesia (Studi Kasus Di Kabupaten Bangka)," SOCA Socioecon. Agric. Agribus., vol. 5, no. 1, pp. 1-21, 2005.

[4] V. Chintyasari, Y. S. Pranoto, and F. Agustina, "Hubungan Kompetensi dengan Peran Penyuluh Pertanian dalam Mengembalikan Kejayaan Lada Putih (Muntok White Pepper) di Provinsi Kepulauan Bangka Belitung,” J. Integr. Agribus., vol. 1, no. 1, pp. 52-66, 2019, doi: 10.33019/jia.v1i1.987.

[5] D. Y. Dalimunthe, D. Valeriani, and S. Wardhani, "Kesiapan Infrastruktur Pendukung pada Destinasi Wisata dalam Mewujudkan Sustainable Tourism Development," vol. 8, no. 1, pp. 227-244, 2020.

[6] D. Valeriani, R. S. Wardhani, D. Y. Dalimunthe, F. Hartini, and D. Reeve, "Infrastructure Readiness To Support Sustainable Tourism Destinations in Bangka Belitung Islands," Int. J. Appl. Sci. Tour. Events, vol. 4, no. 1, p. 12, 2020, doi: 
10.31940/ijaste.v4i1.1908.

[7] D. Y. Dalimunthe and H. Aldila, "Projection and Analysis of National Energy Consumption Levels on Indonesia's Economic Growth Rate through Exponential Smoothing Approach,” IOP Conf. Ser. Earth Environ. Sci., vol. 353, no. 1, 2019, doi: $10.1088 / 1755-1315 / 353 / 1 / 012056$.

[8] D. Y. DALIMUNTHE, "Fit of Statistical Forecasting Model Berdasarkan Variabel Angka Kemiskinan Di Provinsi Kepulauan Bangka Belitung,” E-Jurnal Mat., vol. 9, no. 2, p. 117, 2020, doi: 10.24843/mtk.2020.v09.i02.p288.

[9] D. Y. Dalimunthe, "Data Forecasting Analysis of Gross Regional Domestic Product (Pdrb) As a Reject Measure of Economic Performance of Bangka Belitung Islands Province," Integr. J. Bus. Econ., vol. 1, no. 1, pp. 19-27, 2017, doi: https://doi.org/10.5281/zenodo.322604.

[10] D. Valeriani, D. Y. Dalimunthe, A. Wulandari, and M. F. Ashar, "Vector auto regression analysis between export, economic growth, and job opportunity in bangka belitung islands province," Humanit. Soc. Sci. Rev., vol. 7, no. 4, pp. 677-684, 2019, doi: 10.18510/hssr.2019.7487.

[11] E. Spiliotis, A. Kouloumos, V. Assimakopoulos, and S. Makridakis, "Are forecasting competitions data representative of the reality?," Int. J. Forecast., no. xxxx, 2019, doi: 10.1016/j.ijforecast.2018.12.007.

[12] A. Purba, "Perancangan Aplikasi Peramalan Jumlah Calon Mahasiswa Baru yang mendaftar menggunakan Metode Single Exponential Smoothing (Studi Kasus: Fakultas Agama Islam UISU),” J. Ris. Komput., vol. 2, no. 6, pp. 8-12, 2015.

[13] B. Billah, M. L. King, R. D. Snyder, and A. B. Koehler, "Exponential smoothing model selection for forecasting," Int. J. Forecast., vol. 22, no. 2, pp. 239-247, 2006, doi: 10.1016/j.ijforecast.2005.08.002.

[14] C. Beaumont, S. Makridakis, S. C. Wheelwright, and V. E. McGee, "Forecasting: Methods and Applications," J. Oper. Res. Soc., vol. 35, no. 1, p. 79, 1984, doi: 10.2307/2581936.

[15] S. Kim and H. Kim, "A new metric of absolute percentage error for intermittent demand forecasts," Int. J. Forecast., vol. 32, no. 3, pp. 669-679, 2016, doi: 10.1016/j.ijforecast.2015.12.003. 